\title{
APLICAÇÕES E IMPLICAÇÕES DO OZÔNIO NA INDÚSTRIA, AMBIENTE E SAÚDE
}

\author{
Manoel J. A. Lima ${ }^{a}$, Erika P. Felix ${ }^{a}$ e Arnaldo A. Cardoso, ${ }^{b, *}$, \\ a'Departamento Acadêmico de Química e Biologia, Universidade Tecnológica Federal do Paraná, 81280-340 Curitiba - PR, Brasil \\ bDepartamento de Química Analítica, Instituto de Química de Araraquara, Universidade Estadual Paulista Júlio de Mesquita Filho, \\ 14800-060 Araraquara - SP, Brasil
}

Recebido em 26/11/2020; aceito em 29/03/2021; publicado na web em 28/04/2021

\begin{abstract}
OZONE APPLICATIONS AND IMPLICATIONS FOR INDUSTRY, ENVIRONMENT, AND HEALTH. Stratospheric ozone is an efficient filter for ultraviolet radiation, which damages organisms' lives exposed to sunlight. In the troposphere, ozone is essential to oxidate volatile organic compounds, but its effects are harmful to animals and plants, particularly humans. The high reactivity of ozone with some organic compounds makes it a promising agent for several applications, such as microbiological control and the medical field. However, their contact with surfaces containing unsaturated substances and other compounds can result in the formation of products that are harmful to human health or distort the organoleptic and structural properties of food. The results available in the literature are often divergent as to their safety and economic viability. Despite this, there are many cases of dermatological applications, and as sanitizing agents in several environments. Antiviral and bactericide properties were that guided the expansion of ozone application in the current coronavirus pandemic (COVID-19). However, more studies should be carried out to comprove its effectiveness, considering possible damages resulting from these applications.
\end{abstract}

Keywords: public health; sanitizing agent; ozone therapy; photochemical pollution.

\section{INTRODUÇÃO}

A troposfera (camada da atmosfera com cerca de 10 a $15 \mathrm{~km}$ acima do nível do mar) é constituída por uma variedade de gases e partículas, os quais podem ser emitidos diretamente (primários) ou formados como produto de reações químicas na atmosfera (secundários). Eles são denominados poluentes atmosféricos quando se apresentam em níveis de concentração que os tornem nocivos à saúde humana e danosos aos materiais, animais e vegetais. ${ }^{1}$ Os poluentes primários e secundários podem ocasionar efeitos deletérios aos organismos vivos; esse é o caso do ozônio $\left(\mathrm{O}_{3}\right)$, que embora seja potencialmente danoso sozinho, sua ação aumenta na presença de compostos orgânicos voláteis (COVs) e dióxido de nitrogênio $\left(\mathrm{NO}_{2}\right)$, moléculas precursoras que favoreceram sua formação na troposfera. ${ }^{2-5}$

O ozônio, em altas concentrações, é um gás de coloração levemente azulada. No estado líquido, fase em que assume caráter explosivo, é azul, enquanto no estado sólido, apresenta a cor violetaescuro. Seus pontos de fusão e ebulição são respectivamente $-192{ }^{\circ} \mathrm{C}$ e $-112{ }^{\circ} \mathrm{C}$. Possivelmente, o odor pungente do ozônio ajudou na sua descoberta. Em experimentos envolvendo eletricidade e faíscas elétricas, conduzidos pelo químico Martinus van Marum em 1785, foi relatado um odor peculiar, que em 1839 Christian Friedrich Schönbein chamou de "ozônio", palavra de origem grega que significa cheirar. ${ }^{6}$ Seu odor bastante forte, possibilita sua detecção por olfato até mesmo em concentrações inferiores a $0,5 \mathrm{ppm}$ em volume de ar. $^{7} \mathrm{O}$ ozônio é um gás altamente oxidante $\left(\mathrm{E}^{0}=2,1 \mathrm{~V}\right)$ e possui a capacidade de clivar ligações duplas entre carbonos $(>\mathrm{C}=\mathrm{C}<)$. Essas características o tornam excelente no tratamento de efluentes e como agente desinfetante para obtenção de água potável. O ozônio e o cloro estão entre os agentes mais usados em processos para obtenção de água potável no mundo. Os principais métodos utilizados para produção de ozônio são baseados em descarga elétrica, irradiação ultravioleta (UV) ou por efeito corona; este último tem sido o mais usado. ${ }^{8}$ No ambiente, o ozônio está presente em maior quantidade

*e-mail: arnaldo.cardoso@unesp.br na estratosfera, onde é responsável pela absorção de grande parte dos raios ultravioleta do sol, que são danosos aos animais e vegetais. Preservar o ozônio na estratosfera é essencial para a vida na Terra. Entretanto, sua presença na troposfera em concentrações elevadas, pode ter efeitos nocivos aos organismos vivos e ocasionar problemas ao ambiente. ${ }^{9-11}$ Estudos demonstraram que o $\mathrm{O}_{3}$ é responsável por grande parte da poluição fotoquímica, ocasionando danos mesmo em concentrações abaixo dos atuais limites preconizados pelas agências ambientais. ${ }^{10,12}$ Além disso, há evidências de que os efeitos da exposição ao $\mathrm{O}_{3}$ podem ser intensificados na presença de outros componentes atmosféricos. Existem também relatos baseados na comparação entre os prejuízos causados pelo $\mathrm{O}_{3}$ ou por atmosferas contendo misturas de aerossóis e $\mathrm{NO}_{2}$, sugerindo um efeito sinérgico na presença de outros poluentes, mesmo em níveis conhecidamente não prejudiciais para a substância isolada. ${ }^{13,14}$

Para pessoas sem morbidades, a variabilidade na concentração de ozônio pode ser imperceptível; no entanto, para grupos susceptíveis, como asmáticos, idosos, cardíacos, ${ }^{15}$ entre outros, pode acarretar em graves efeitos colaterais. ${ }^{16}$ Estudos detalhados feitos por cerca de 14 anos, em 95 comunidades urbanas dos Estados Unidos da América (EUA), mostraram os dados de mortalidade relacionados com a concentração de ozônio troposférico. ${ }^{17}$ Os autores afirmaram que um aumento de 10 ppb em uma exposição a curto prazo ao ozônio, pode contribuir com $0,52 \%$ na mortalidade. Outros autores avaliaram dados de cidades europeias e verificaram que uma exposição a 25,5 ppb estava relacionada com um aumento na mortalidade de até $2,9 \% .^{18}$

A importância da qualidade do ar tem resultado em preocupação junto aos órgãos legisladores pelo mundo. Na União Europeia (UE), o valor alvo para a concentração máxima média móvel de ozônio em 8 horas é de $120 \mu \mathrm{g} \mathrm{m}^{-3}$, enquanto a Organização Mundial da Saúde (OMS) estabelece $100 \mu \mathrm{g} \mathrm{m}{ }^{-3} \cdot{ }^{19,20}$ A Agência de Proteção Ambiental dos Estados Unidos (EPA, United States Environmental Protection Agency) estabelece um valor máximo de 0,070 ppm (ca. $\left.137 \mu \mathrm{g} \mathrm{m}^{-3}\right) .{ }^{21}$ No Brasil, o Conselho Nacional do Meio Ambiente (CONAMA) estabelece $140 \mu \mathrm{g} \mathrm{m}^{-3}$ como máxima concentração 
média móvel de ozônio durante 8 horas, com perspectiva de reduzir esse valor para $100 \mu \mathrm{g} \mathrm{m}^{-3} .^{22}$

Apesar da alta letalidade do ozônio, quando inalado mesmo em baixas concentrações, seu uso tem sido sugerido para solucionar diversos problemas do mundo moderno. Isso decorre, possivelmente, das suas qualidades como agente germicida, bactericida e de limpeza química, além do baixo custo, portabilidade e facilidade de operação dos ozonizadores. Equipamentos residenciais para purificação de água e desodorizantes de ambientes são comumente encontrados no comércio. Porém, sua aplicação que mais tem crescido é em tratamentos médicos e odontológicos. Em 2016, a "Food and Drug Administration" proibiu o uso medicinal de ozônio, afirmando tratarse de um gás tóxico, sem aplicação médica conhecida, mesmo como terapia auxiliar, e também desaconselha seu uso como germicida. ${ }^{23}$ No Brasil, o Ministério da Saúde inclui a ozonioterapia dentre as práticas integrativas e complementares que são custeadas pelo Sistema Único de Saúde. A Portaria N N $^{\circ}$ 202, 21 de março de 2018 do Ministério da Saúde, descreve essa prática como "de baixo custo, segurança comprovada e reconhecida, que utiliza a aplicação de uma mistura dos gases oxigênio e ozônio, por diversas vias de administração (...). A molécula de ozônio é molécula biológica, presente na natureza e produzida pelo organismo sendo que o ozônio medicinal, nos seus diversos mecanismos de ação, representa um estímulo que contribui para a melhora de diversas doenças, uma vez que pode ajudar a recuperar de forma natural a capacidade funcional do organismo humano e animal". Observação: os destaques foram dados pelos autores deste artigo.

Durante o ano de 2020, impulsionado pela necessidade de respostas rápidas e eficientes para desinfectar ambientes de possíveis contaminações com o novo coronavírus (COVID-19), têm-se buscado alternativas diversas para os procedimentos de descontaminação de materiais e ambientes. A produção de câmaras ou túneis para pulverização de ozônio em humanos e/ou equipamentos de proteção, a higienização de automóveis e de ambientes fechados, ou até mesmo um traje para descontaminação têm sido desenvolvidos. No entanto, pouca atenção tem sido dada a toxicidade do ozônio, formação de subprodutos, nível de concentração segura e precauções necessárias. A literatura é bastante extensa e controversa em relação a estes pontos. Nesse sentido, a presente revisão visa ampliar a discussão sobre a real necessidade do emprego indiscriminado do ozônio, especialmente a que coloca a população em contato direto com essa substância ou seus subprodutos. Outro aspecto a ser considerado é o risco/ganho efetivo, ao empregar este poderoso oxidante em diversos processos.

\section{OZÔNIO NA TROPOSFERA}

Diversos oxidantes podem ser encontrados no ar ambiente, sendo os principais: $\mathrm{O}_{3}, \mathrm{H}_{2} \mathrm{O}_{2}, \mathrm{HO}^{\bullet}, \mathrm{HO}_{2}{ }^{\bullet}, \mathrm{NO}_{3}{ }^{\bullet}$ e nitrato de peroxiacetil (PAN). $\mathrm{O} \mathrm{O}_{3}$ está envolvido diretamente ou indiretamente em diversas cadeias de oxidação primárias que ocorrem na atmosfera para formação desses oxidantes. ${ }^{9}$ A geração do ozônio na troposfera ocorre através da interação de $\mathrm{NO}_{2}$ com a radiação eletromagnética (entre 295 e $430 \mathrm{~nm}$ ), formando óxido nítrico (NO•) e oxigênio atômico $\left(\mathrm{O}^{*}\right)$, que ao reagir com oxigênio molecular $\left(\mathrm{O}_{2}\right)$ produz $\mathrm{O}_{3}$, conforme equações (1) e (2), em que Mé uma molécula que absorve o excesso de energia (geralmente $\mathrm{N}_{2}$ ou $\mathrm{O}_{2}$ ). ${ }^{24,25}$

$$
\begin{gathered}
\mathrm{NO}_{2}+h v(\lambda<430 \mathrm{~nm}) \rightarrow \mathrm{NO}+\mathrm{O} \\
\mathrm{O}+\mathrm{O}_{2}+\mathrm{M} \rightarrow \mathrm{O}_{3}+\mathrm{M}
\end{gathered}
$$

Em atmosferas limpas, o $\mathrm{NO}_{2}$ é formado por meio da reação de oxidação do $\mathrm{NO}$ pelo $\mathrm{O}_{3}$, de modo que sua fotodecomposição (equação 1), a formação do $\mathrm{O}_{3}$ (equação 2) e seu posterior consumo, através da reação com NO (equação 3), resultam em um estado estacionário. ${ }^{26,27}$

$$
\mathrm{NO}+\mathrm{O}_{3} \rightarrow \mathrm{NO}_{2}+\mathrm{O}_{2}
$$

$\mathrm{O}$ aumento na concentração de $\mathrm{O}_{3}$ na troposfera deve-se à presença de quantidades significativas de $\mathrm{NO}_{x}$ e COVs, os quais são emitidos a partir de fontes antrópicas diversas e também são liberados de forma natural pela vegetação. Esses compostos competem com o ozônio na oxidação do $\mathrm{NO}$ para formação do $\mathrm{NO}_{2} \cdot{ }^{28}$ Como resultado, o equilíbrio fotoestacionário é quebrado e a concentração do ozônio aumenta, principalmente quando a relação entre $\mathrm{COVs} / \mathrm{NO}_{\mathrm{x}}$ tende a excessos de COVs. ${ }^{29}$

$\mathrm{O} \mathrm{O}_{3}$ formado promove diversas cadeias de reações atmosféricas. A principal reação é iniciada pela fotólise do ozônio em presença de vapor d'água, gerando radicais hidroxil (equação 5). ${ }^{24,28}$

$$
\begin{gathered}
\mathrm{O}_{3}+h v(\lambda \leq 320 \mathrm{~nm}) \rightarrow \mathrm{O}^{*}+\mathrm{O}_{2} \\
\mathrm{O}^{*}+\mathrm{H}_{2} \mathrm{O} \rightarrow 2 \mathrm{HO}^{*}
\end{gathered}
$$

A contribuição dos radicais $\mathrm{HO}^{\bullet}$ na oxidação dos COVs, que resulta na conversão do $\mathrm{NO}$ a $\mathrm{NO}_{2}$ e, consequentemente, no incremento na concentração de $\mathrm{O}_{3}$, pode ser descrita em um modelo simplificado na sequência de reações radicalares (equação 6).

$$
\begin{gathered}
\mathrm{RH}+\mathrm{HO}^{\bullet} \rightarrow \mathrm{H}_{2} \mathrm{O}+\mathrm{R}^{\bullet} \\
\mathrm{R}^{\bullet}+\mathrm{O}_{2} \rightarrow \mathrm{RO}_{2}^{\bullet} \\
\mathrm{RO}_{2}^{\bullet}+\mathrm{NO} \rightarrow \mathrm{NO}_{2}+\mathrm{RO}^{\bullet} \\
\mathrm{RO}^{\bullet}+\mathrm{O}_{2} \rightarrow \mathrm{HO}_{2}^{\bullet}+\mathrm{RCHO}^{\circ} \mathrm{RCOR} \\
\mathrm{HO}_{2}^{\bullet}+\mathrm{NO} \rightarrow \mathrm{NO}_{2}+\mathrm{HO}^{\bullet}
\end{gathered}
$$

Os COVs (RH) entram na cadeia de oxidação pela reação com os radicais $\mathrm{HO}^{*}$, iniciadores das reações que, posteriormente, resultam na formação do $\mathrm{O}_{3}$. Os radicais orgânicos formados $\left(\mathrm{R}^{*}\right)$ geram radicais peróxi $\left(\mathrm{RO}_{2} \cdot \mathrm{e} \mathrm{HO}_{2}{ }^{\bullet}\right)$, os quais são responsáveis pela oxidação do $\mathrm{NO}$ a $\mathrm{NO}_{2}$. Concentrações altas de COVs resultam na maior produção de $\mathrm{O}_{3}$ na troposfera, pois os radicais peróxi formados atuam como oxidantes de NO, aumentando, desta forma, a concentração da molécula precursora de $\mathrm{O}_{3}$ na troposfera $\left(\mathrm{NO}_{2}\right)$ e minimizando a principal via de eliminação do ozônio formado (equação 3), que envolve a conversão do $\mathrm{NO}$ a $\mathrm{NO}_{2} \cdot{ }^{9} \mathrm{O}$ aumento do ozônio na troposfera é consequência dessas reações e produto da emissão indiscriminada de COVs e NO por atividades antrópicas. Estudos sobre o ozônio troposférico relatam que aos fins de semana, devido ao menor fluxo de veículos movidos a diesel (reconhecido emissor de $\mathrm{NO}_{\mathrm{x}}$ ), ocorre um aumento nas concentrações de $\mathrm{O}_{3}$, o que mostra o papel importante do NO no consumo de ozônio e formação do $\mathrm{NO}_{2} \cdot{ }^{29-31}$ Intrusões estratosféricas de ozônio na troposfera também são bem documentadas na literatura, podendo atingir o solo, elevando substancialmente a sua concentração no ambiente..$^{32,33} \mathrm{O}$ resultado é que os padrões de qualidade do ar podem ser ultrapassados em um curto intervalo de tempo. Esses fenômenos não são difíceis de acontecer e são mais frequentes em locais de altitude elevada. ${ }^{33}$

\section{O PODER OXIDANTE DO OZÔNIO EM MEIO AQUOSO}

O ozônio é moderadamente solúvel em água $\left(12 \mathrm{mg} \mathrm{dm}^{-3} ; 25^{\circ} \mathrm{C}\right)$, além de formar uma solução pouco estável na sua forma dissolvida. Parte dele é perdido por evaporação e outra parte por reações em cadeia com moléculas de água. Inicialmente, o ozônio reage com os íons $\mathrm{OH}^{-}$da água para formar os radicais $\mathrm{HO}_{2} \cdot \mathrm{e}_{2} \cdot{ }^{\bullet}$ (equação 7), que subsequentemente participam de uma série de reações radicalares em cadeia. O radical hidroxila (HO•) e as moléculas de ozônio dissolvidas 
são as principais espécies envolvidas em diferentes reações de oxidação da matéria orgânica presente no meio aquoso. ${ }^{34}$

$$
\begin{aligned}
& \mathrm{O}_{3}+\mathrm{OH}^{-} \longrightarrow \mathrm{HO}_{2}{ }_{2}+\mathrm{O}_{2}^{-} \\
& \left.\int \mid \mathrm{pK}_{\mathrm{a}}=4,8\right] \\
& \cdot \mathrm{O}_{2}{ }^{-}+\mathrm{H}^{+}
\end{aligned}
$$

Além da geração de um poderoso oxidante (HO•), o ozônio solúvel na água reage com compostos aromáticos e alifáticos insaturados, polissacarídeos, álcoois, ácidos graxos insaturados, nucleobases e também pode reagir com $\mathrm{H}_{2} \mathrm{O}_{2}, \mathrm{Fe}^{3+}$, $\mathrm{HO}^{-}$e/ou radiação $\mathrm{UV}$, dando início aos processos de oxidação avançados (POA), que são amplamente empregados na degradação da matéria orgânica. ${ }^{35}$ Inúmeros trabalhos descrevem os processos que ocorrem na solubilização do ozônio na água e suas reações diretas e indiretas. Portanto, a qualidade da água, bem como a presença de íons metálicos, substâncias orgânicas e o pH devem ser rigorosamente controlados; caso contrário, uma grande quantidade de produtos indesejáveis pode estar presente no meio.

\section{MÉTODOS DE ANÁLISE DO OZÔNIO}

O ozônio é um gás que pela sua alta reatividade não pode ser coletado e guardado. Para que seja possível sua análise via reações químicas, é necessário usar um composto para reagir previamente com o ozônio de forma quantitativa. Posteriormente, o produto formado na reação deve ser passível de determinação por alguma técnica analítica. O método clássico de reação do ozônio com iodeto de potássio envolve a formação do íon triiodeto $\left(\mathrm{I}_{3}^{-}\right)$, que pode ser determinado através de medidas de absorbância na região do ultravioleta. Esse método é aplicável à análise de oxidantes totais, representados como ozônio, e o limite de detecção (LD) está na faixa de 0,01 a 10 ppm. ${ }^{36}$

Reações de ozonólise são também usadas na determinação de ozônio. Compostos orgânicos contendo dupla ligação, ao reagirem com ozônio liberam compostos carbonílicos, que podem ser determinados por espectrofotometria UV-vis. Estudos envolvendo diferentes alcenos mostraram que quando o composto olefínico usado é o 4-alil-2-metoxifenol (eugenol), o produto gerado é o formaldeído, que pode ser convenientemente determinado com um reagente seletivo. ${ }^{37}$

O método clássico para a determinação de ozônio dissolvido em água utiliza o corante índigo trissulfonado (ITS). A molécula do corante tem uma dupla ligação, que é responsável pela sua cor azul; o ozônio degrada a molécula do índigo, resultando em compostos incolores. ${ }^{38}$

Para o ozônio na forma de gás, a reação com o índigo foi adaptada tanto para amostragens ativas, usando uma bomba de aspiração de ar, como para amostragens passivas. Felix e colaboradores utilizaram filtros de celulose impregnados com ITS para coleta ativa de ozônio. A posterior determinação espectrofotométrica resultou em um LD de até 6 ppbv. ${ }^{39}$ Estudos mostraram que o ITS reage com ozônio produzindo uma espécie fluorescente, o que possibilitou sua quantificação por espectrometria de fluorescência molecular (LD de 7 ppbv). ${ }^{40} \mathrm{Um}$ sensor colorimétrico, acoplado a uma gota formada com solução de ITS, apresentou resposta rápida para determinação de ozônio, com tempo total de análise de 5 min, e LD de 7,3 ppbv. ${ }^{41}$ Garcia e colaboradores ${ }^{42}$ desenvolveram um amostrador passivo para coleta de $\mathrm{O}_{3}$, usando filtros de celulose tratados com solução de ITS. Coletas simultâneas, realizadas com o método proposto e o método oficial, mostraram um coeficiente de correlação de 0,957 e um desvio padrão relativo médio de 8,6\% $(\mathrm{n}=3)$. Esse método foi otimizado para detecção por imagens, ${ }^{43}$ com concentrações de índigo determinadas diretamente nos filtros por comparação com um padrão de cores. De forma similar, o ITS pode ser utilizado para a determinação de ozônio por meio de imagens digitais registradas com a câmera de um smartphone ${ }^{44}$ ou pela voltametria de onda quadrada usando um potenciostato portátil. ${ }^{45}$ Esses procedimentos apresentaram boas figuras de mérito, baixo custo e praticidade nas análises, tornando-os adequados para utilização em amostras in situ.

Outro método desenvolvido para a determinação de ozônio envolve a oxidação de íons nitrito a nitrato, e posterior quantificação por cromatografia iônica ou eletroforese capilar. Essa última técnica foi proposta em substituição à cromatografia por melhorar a velocidade da análise e usar um volume reduzido de amostra ${ }^{46}$ Estudos realizados na região da Europa Central, envolvendo a coleta do ozônio usando filtros impregnados com solução de $\mathrm{NO}_{2}^{-}$, mostraram uma grande variação na concentração de $\mathrm{O}_{3}$ entre os diferentes locais e em relação a altitude. ${ }^{47} \mathrm{O}$ mesmo método foi aplicado em duas cidades da Suécia e os autores concluíram que as concentrações de ozônio sofreram maiores variações em função do período de coleta do que do local de amostragem. ${ }^{48}$ Cabe ressaltar que embora esse método apresente alta sensibilidade e emprego de reagentes de uso comum, a determinação de nitrato por cromatografia iônica requer equipamento de alto custo de aquisição e manutenção. Recentemente, fitas sensíveis a presença de ozônio estão comercialmente disponíveis e podem fornecer resposta qualitativa em um curto intervalo de tempo (ca. $10 \mathrm{~min}$ ), com limite de quantificação (LQ) de aproximadamente 45 ppb. ${ }^{49}$ Para medições semi-quantitativas, tubos semelhantes a pipetas graduadas, com reagentes sólidos empacotados e alta afinidade por ozônio, também estão disponíveis. Esses tubos podem ser facilmente adaptados a bombas de ar em uma etapa de amostragem ( $<10 \mathrm{~min})$, em seguida a leitura visual pode ser realizada diretamente na escala contida na parede do tubo (LD $10 \mathrm{ppb}$ ), pela nítida mudança na coloração do sólido interno. ${ }^{50}$ Assim, a colorimetria como técnica de quantificação, empregando equipamentos de baixo custo, como por exemplo scanners e câmeras de smartphones, tem se mostrado mais viável quando comparada a técnicas convencionais, o que possibilita a ampliação das análises em diferentes ambientes.

\section{CONSEQUÊNCIAS DA REATIVIDADE DO OZÔNIO}

O ozônio apresenta elevada atividade oxidante, reagindo vigorosamente com compostos orgânicos contendo duplas ligações, para formar compostos denominados ozonídeos, que, por serem bastante instáveis, são rapidamente convertidos a compostos carbonílicos (aldeídos e cetonas). Essas características conferem ao ozônio intensa reatividade com diversos materiais e, inclusive, com sistemas biológicos. ${ }^{51,52}$ Em solução aquosa, o ozônio forma os radicais $\mathrm{HO}_{2}{ }^{\bullet} \mathrm{e}_{2}{ }^{\bullet}$, que reagem com a matéria orgânica, promovendo sua degradação. A presença de íon metálicos, radiação UV, meio alcalino e outras variáveis podem acelerar os processos de oxidação da matéria orgânica. ${ }^{53}$

\section{Saúde humana}

No ser humano, a principal via de entrada dos poluentes atmosféricos é através do trato respiratório. O mecanismo de atuação desses poluentes depende das características químicas e físicas das espécies e da sua interação com os componentes biológicos. No caso do $\mathrm{O}_{3}$, os principais efeitos ocorrem pelo contato com as vias aéreas e mucosas. Seus alvos são as estruturas insaturadas, como moléculas de ácidos graxos e de proteínas, que são constituintes das membranas biológicas. Desse modo, a exposição ao $\mathrm{O}_{3}$ pode causar danos a todas as células do trato respiratório $;{ }^{54}$ porém, isso depende da concentração do gás e do tempo de exposição. Os efeitos podem assumir caráter agudo ou crônico, ambos constatados em estudos epidemiológicos. ${ }^{1,17}$ Os efeitos da exposição aguda mais importantes 
são: lesões celulares (principalmente na região alveolar), morte das células pulmonares e aumento das taxas de replicação (hiperplasia), decréscimo na atividade pulmonar, inflamação das vias respiratórias e aparecimento de sintomas como tosse, dor no peito, dificuldade em realizar movimentos inspiratórios profundos e, por vezes, acompanhado de cefaleia e náuseas. ${ }^{55}$ Dentre os efeitos crônicos, os mais estudados são a incidência de asma e o câncer de pulmão. ${ }^{56}$

Relatos da literatura mostram que a exposição prolongada ao $\mathrm{O}_{3}$, via inalação, danifica o sistema respiratório e órgãos extrapulmonares. ${ }^{57}$ Lesões epiteliais induzidas por $\mathrm{O}_{3}$ são também amplamente discutidas e os principais resultados apontam para danos e alterações morfológicas nas células epiteliais pulmonares. ${ }^{58}$ Além disso, a permeabilidade alveolar (danificação da superfície epitelial) foi confirmada pelo aparecimento de células de Clara na corrente sanguínea, visto que essas células estão originalmente presentes na superfície do pulmão. ${ }^{10,59}$ Esses dados são preocupantes, uma vez que indicam a permeação do ozônio através do epitélio, mostrando que a atividade antioxidante pode não ser suficientemente efetiva em sua neutralização. Resultados recentes indicam que até mesmo concentrações 40 vezes menores que as consideradas seguras pelas agências ambientais, em um intervalo de tempo de $2 \mathrm{~h}$ (i.e., 0,05 e 0,005 ppm), influenciam negativamente o sistema respiratório, desencadeando uma série de anomalias e resposta inflamatória em camundongos. ${ }^{12}$

O efeito do ozônio em contato com a pele também já foi avaliado por diversos autores e os estudos confirmaram a perda dos antioxidantes presentes na pele, através de um intenso estresse oxidativo. ${ }^{60}$ Esses efeitos podem ser intensificados em pessoas que vivem em países tropicais com alta incidência de raios solares, onde a radiação UV e a presença de $\mathrm{O}_{3}$ são significativas. $\mathrm{O}$ contato do $\mathrm{O}_{3}$ com os fluidos epiteliais promove a ozonólise (via mecanismo de Criegee), ${ }^{51,53}$ ao reagir com os ácidos graxos insaturados e colesterol, podendo gerar espécies reativas de oxigênio. ${ }^{51,52}$ Essas espécies promovem a formação de aldeídos e radicais livres por meio da peroxidação lipídica (hidroxi-5-oxo-5,6-secocolestan-6-al (colesterol secoaldeído), produto majoritário), que está relacionada aos diagnósticos da doença de Alzheimer, aterosclerose e também a toxicidade pulmonar (Figura 1). ${ }^{61,62}$ Prior W. A. ${ }^{51}$ relata que provavelmente os danos causados pelo $\mathrm{O}_{3}$ correspondam a no máximo $50 \%$ dos efeitos totais (toxicidade direta), e que as espécies geradas durante a oxidação (i.e., aldeídos, peróxido de hidrogênio e outras) são responsáveis pela outra parte.

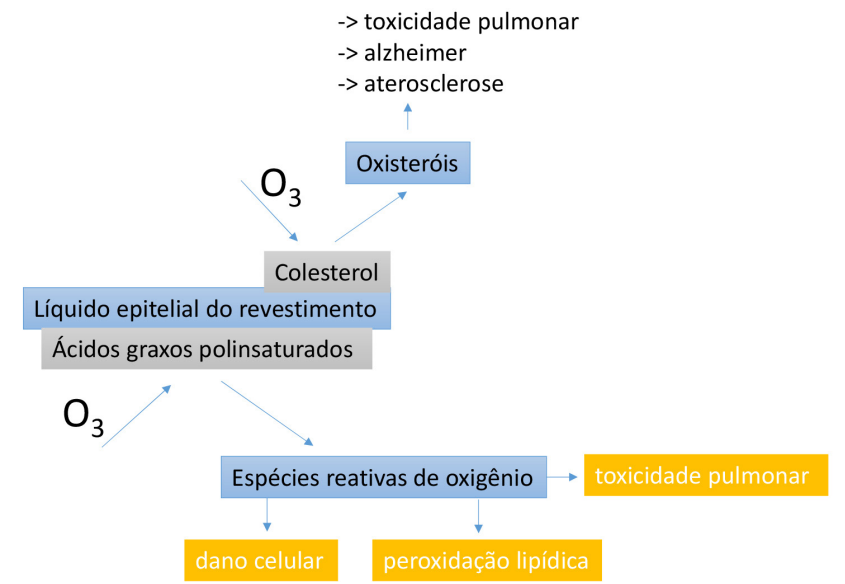

Figura 1. Esquema da interação do ozônio com fluidos epiteliais e principais efeitos. Informações baseadas nas referências. ${ }^{51,52,61-63}$

Deve ser destacado que grupos de pessoas sensíveis (por exemplo, idosos e indivíduos com problemas cardiovasculares, asmáticos ou com doenças que comprometam o sistema respiratório) são afetados diretamente pela variabilidade da qualidade do ar e estão mais susceptíveis aos efeitos devastadores da presença do $\mathrm{O}_{3}$, seja por exposição pontual ou crônica. ${ }^{57}$ Esses fatores aumentam os níveis de internação, além de estarem relacionados aos óbitos, devido ao agravamento de quadros clínicos mais críticos. Nesse sentido, estudos relacionam a presença de $\mathrm{O}_{3}$ no ambiente com o indevido crescimento dos pulmões e o decréscimo da função pulmonar. Efeitos adversos são relatados até para prematuros, que possuem maior risco de problemas respiratórios e parecem ser substancialmente mais vulneráveis aos efeitos da poluição. ${ }^{16}$

\section{Ambiente}

O ozônio está entre os poluentes atmosféricos com maior potencial fitotóxico, ao lado do $\mathrm{SO}_{2}, \mathrm{NO}_{2}$, fluoretos e PAN. ${ }^{64}$ Diversos fatores podem aumentar ou diminuir a ação do ozônio, como espécie, idade e balanço nutricional do vegetal. ${ }^{65}$ A região mais afetada são os estômatos presentes nas folhas, pois são responsáveis pelas trocas gasosas no vegetal e possivelmente atuam como sumidouro para o ozônio troposférico. ${ }^{66}$ Por esse motivo, os efeitos desse poluente concentram-se nas folhas, ocorrendo perda de cor em vários níveis e, até mesmo, necrose dos tecidos. ${ }^{67-69}$ Folhas de coníferas expostas a 30 ppb de ozônio, durante 4 horas, apresentaram manchas esbranquiçadas (descoramento), pigmentação e necrose da sua porção mais pontiaguda. Em espécies comerciais, como alface, tabaco e orquídeas, a ação do ozônio implica diretamente em prejuízos econômicos. Em culturas de uva, batata e milho, pode resultar em lesões aparentes nas folhas, mas não no produto final. ${ }^{65}$

O ozônio provoca danos a diversos materiais, especialmente aqueles constituídos por compostos contendo ligações insaturadas, como borrachas e corantes. $\mathrm{O}$ ozônio promove o ataque oxidativo às ligações duplas $(>\mathrm{C}=\mathrm{C}<$ ), resultando em uma borracha quebradiça ou descorando tintas. ${ }^{55} \mathrm{O}$ problema é particularmente crítico para obras de arte, que causam grandes prejuízos econômicos. ${ }^{70-72}$

\section{USOS DO OZÔNIO}

O ozônio, devido ao seu comprovado efeito oxidante, é capaz de eliminar fungos, bactérias e outros microrganismos que afetam o homem. Possui uma ampla aplicação como desinfetante, conservante, agente de branqueamento, em indústrias têxteis, alimentícias etc. ${ }^{73,74}$ Os primeiros usos do ozônio em processos de desinfecção eram quase que exclusivamente destinados ao tratamento de águas e esgotos. ${ }^{53} \mathrm{~A}$ sua desvantagem como agente desinfetante para produção de água potável está relacionada com a sua alta reatividade e, consequentemente, com seu curto tempo de vida pós-tratamento. Apesar disso, alguns países optaram por utilizar ozônio em estações de tratamento. As vantagens da cloração, usada em países como o Brasil, são o menor custo e o poder residual do cloro pós-tratamento, que pode chegar até a torneira do usuário. Possivelmente, a aplicação de ozônio em ambientes controlados e seguros de empresas de tratamento de águas ajudou na propaganda de ozonizadores para uso doméstico. Esses equipamentos não possuem qualquer especificação sobre a quantidade mínima de água que deve ser "ozonizada", fato que pode resultar em grande perda de ozônio para o ambiente. Logo outras aplicações foram incorporadas para ampliar o uso dos ozonizadores, como descrito em informações do produto "perfeito para remover odores e mau cheiro de geladeira, cozinha, quartos, guarda roupas, banheiros para eliminar mofo etc."

\section{Ozonioterapia}

No início do século XX surgiu a ozonioterapia, que consiste em explorar possíveis efeitos farmacológicos e clínicos benéficos 
associados ao ozônio. As aplicações iniciais eram voltadas para tratamentos de feridas e infecções cutâneas provocadas por bactérias anaeróbicas, sendo uma alternativa aos métodos tradicionais que não apresentavam os efeitos desejáveis. No início da Primeira Guerra Mundial, um hospital militar em Londres testou o ozônio como desinfetante para feridas. O gás foi aplicado diretamente nas feridas por até 15 minutos. $\mathrm{O}$ efeito positivo, que resultou na eliminação de bactérias, ficou comprometido pelos danos negativos ao tecido humano. ${ }^{75}$ Apesar das evidências contrárias aos usos do ozônio relatadas na literatura, ${ }^{51,52,61,62}$ o "pai" da terapia com ozônio, Velio Bocci, comenta que a ozonioterapia não é aplicada em larga escala e acompanhada de estudos científicos devido ao baixo interesse econômico da indústria, o que torna o emprego de ozônio não rentável para esse setor. ${ }^{76-78}$ A hipótese dos adeptos a esta prática é de que o estresse oxidativo induzido tenha uma vida útil curta, o que não resultaria em danos. Isto é bastante controverso, já que não é só o tempo o principal fator de uma transformação, mas a reatividade intrínseca do material; porém, cabe ressaltar a necessidade da realização de estudos para confirmação dessas suposições. No que diz respeito aos efeitos do ozônio em aplicações sobre a pele, vários estudos foram publicados ao longo dos anos. Bocci e colaboradores ${ }^{79}$ descreveram que a exposição do corpo humano ao ozônio, exceto o pescoço e a cabeça, durante 20 min em uma câmara com cerca de $0,90 \mu \mathrm{g} \mathrm{mL} \mathrm{m}^{-1}$ do gás, não apresentou efeitos agudos ou crônicos. Nesse experimento, foi notado um aumento da pressão sistólica, aumento sistemático de produtos de peroxidação lipídica (normalizados após 24h) e dificuldade em tolerar maiores tempos de exposição, de acordo com metade dos indivíduos que receberam o tratamento. ${ }^{79}$ Por outro lado, existem relatos de ações benéficas para pacientes com isquemia crônica dos membros, quando eles são submetidos ao contato com ozônio em baixas concentrações e curto intervalo de tempo. ${ }^{60,77}$

Os pesquisadores exploraram uma série de estratégias para aplicação do ozônio sobre áreas com difícil cicatrização ou até mesmo infestadas por patógenos. Água ultrapura e óleos recém ozonizados são os mais usados para atuarem como veículos do gás. ${ }^{80}$ No caso dos óleos, os autores relatam que a reação do ozônio com substratos insaturados leva à formação de derivados ozonizados terapeuticamente ativos. A administração destes líquidos é, geralmente, realizada pela exposição cutânea. O uso de óleo e/ou água ozonizada são relatados para tratamento de feridas em pé diabético, ${ }^{81,82}$ antifúngico, antimicrobiano, ${ }^{83}$ cicatrizante $^{84}$ e outros. ${ }^{80}$ São poucos os casos reportados na literatura de efeitos colaterais decorrentes do uso de óleos ozonizados; entretanto, há relato de dermatite perioral, provavelmente induzida pelo uso desse tipo de óleo. ${ }^{85}$

Aplicações da ozonioterapia na área odontológica, para auxiliar na desinfecção e na cicatrização de feridas, além de outras finalidades, têm sido reportadas com sucesso. ${ }^{86,87} \mathrm{O}$ efeito dos óleos ozonizados como bactericidas foram comprovados em experimentos in vitro; no entanto, quando testados, esses óleos não apresentaram sequer traços de ozônio. Por outro lado, testes mostraram grandes quantidades de formaldeído, reconhecido bactericida, porém de uso proibido por ser carcinogênico ${ }^{88} \mathrm{O}$ formaldeído é formado pela reação das cadeias insaturadas do óleo com o ozônio durante o processo de produção ${ }^{89}$ Há relatos também do tratamento de patologias da mucosa vaginal, ${ }^{90}$ possivelmente resultado da atuação do formaldeído. Outra aplicação bastante difundida da ozonioterapia é a auto-hemoterapia. Esse procedimento consiste em retirar uma quantidade de sangue, misturar com o ozônio e, em seguida, reinjetar o sangue ozonizado no paciente. ${ }^{78}$ Os autores relatam que, no passado, acidentes ocorreram pela administração errônea de ozônio gasoso diretamente na corrente sanguínea, provocando embolia pulmonar. No entanto, eles caracterizam o processo de auto-hemoterapia como seguro e sem efeitos colaterais, pois segundo os adeptos desse tratamento, ocorre exposição a uma dose precisamente controlada e segura. ${ }^{76}$ Os autores desses trabalhos apontam diversos benefícios do emprego dessa técnica para tratamento de doenças inflamatórias crônicas, patologias cardiovasculares e outras enfermidades. ${ }^{76-78,91}$

\section{Indústria alimentícia}

A indústria alimentícia tem procurado no ozônio qualidades como agente desinfetante e conservante, explorando sua característica oxidante forte e rápida degradação, sem deixar resíduos. ${ }^{92} \mathrm{~A}$ dissolução do ozônio em água, gelo, ou até mesmo em câmaras gasosas tem sido relatada como agente bactericida, melhorando qualidades sensoriais e/ou conservante (aumento da vida útil) em espécies marinhas frescas, ${ }^{93,94}$ frutas e vegetais, ${ }^{95}$ produtos lácteos, ${ }^{73,96}$ entre outros. ${ }^{97}$ Relatos da literatura sugerem que concentrações adequadas de ozônio poderiam ser usadas não só para remover odores característicos de frutos do mar, mas também para mascarar alimentos impróprios para consumo. Diferentes concentrações de ozônio foram relatadas para o processamento de espécies marinhas, com faixa de 0,05 a $12,0 \mathrm{mg} \mathrm{L}^{-1}$, em diferentes tempos de contato e temperaturas. ${ }^{97}$ Apesar dos resultados promissores, a alta reatividade do ozônio precisa ser considerada na conservação dos produtos do mar. Ele reage com fosfolipídios, ácidos graxos poliinsaturados e proteínas, formando compostos variados como aldeídos, álcoois, corpos cetônicos, peróxidos e outros. ${ }^{98-100}$ Além disso, são bem conhecidos os riscos da oxidação de brometo $(\mathrm{Br})$, espécie comum em organismos marinhos, a bromato $\left(\mathrm{BrO}_{3}^{-}\right)$. Esse íon com o $\mathrm{Br}$ $($ nox +5$)$ possui restrições quanto a sua ingestão, devido ao potencial carcinogênico dessa espécie. ${ }^{92,101}$ É evidente que produtos alimentícios tratados com ozônio requerem um acompanhamento de análises químicas até o consumo. No entanto, os vendedores e fabricantes de ozonizadores, além de blogs correlacionados, não mencionam esse fato por falta de conhecimento ou por falta de legislação sobre isso.

O ozônio gasoso tem sido usado também para combater a presença de micotoxinas em silos que armazenam grãos como milho, amendoim, cevada e outros. ${ }^{102-104}$ Nesse tipo de aplicação, concentrações letais em humanos são relatadas (i.e., 50 ppm). ${ }^{103,105}$ Essa estratégia pode ser aparentemente eficiente eliminando os fungos dos grãos, além de ser descrita como segura para o operador que fica distante do local. De forma similar a outros alimentos, os efeitos como oxidação de proteínas, despolimerização de amilopectinas, aumento na concentração de grupos carboxílicos ${ }^{98,106,107}$ e alterações nas características reológicas e térmicas são aspectos importantes que devem ser considerados em trabalhos que fomentam o uso de ozônio. ${ }^{99}$

A aplicação de ozônio em produtos lácteos também tem sido relatada ${ }^{96,108} \mathrm{e}$, apesar dos resultados promissores, algumas amostras de queijo desenvolveram um sabor desagradável quando expostas ao ozônio, o que inviabilizou sua comercialização. ${ }^{100} \mathrm{Na}$ maioria das aplicações industriais, principalmente as que utilizam o ozônio na fase gasosa, um controle rigoroso dos processos deve ser estabelecido. $\mathrm{O}$ uso de sistemas que detectam a presença do ozônio em concentrações maiores que $0,1 \mathrm{mg} \mathrm{L}^{-1}$ é aconselhável. ${ }^{73}$ Trabalhos de revisão recentes trazem várias aplicações, além das citadas aqui. ${ }^{74,109}$

A complexa química envolvida nas reações do ozônio em contato com compostos orgânicos naturais resulta em uma variedade de produtos, tornado difícil a compreensão dos efeitos. $\mathrm{O}$ contato direto do gás com superfícies contendo gorduras, polímeros, espécies orgânicas ou inorgânicas, pode gerar subprodutos bastante instáveis e/ou tóxicos, ou até mesmo danos nas propriedades do alimento. Em geral, observa-se que os trabalhos que relatam a ozonização como estratégia para higienizar ou conservar os alimentos não tem cuidado de relatar a importância do monitoramento das espécies provenientes desse tratamento. Constata-se apenas uma preocupação 
em aferir a manutenção das características reológicas e térmicas, além dos aspectos organolépticos, que são fundamentais na valorização do produto. Já quando o uso do ozônio é para aplicação em seres humanos, essas reações sequer são mencionadas como uma possibilidade.

\section{Ozônio e pandemia do coronavírus}

A pandemia do coronavírus (COVID-19) se apresentou como uma enfermidade global, pouco conhecida e sem um tratamento eficaz para eliminação do vírus. Como ocorre nestes casos, "especialistas" sugerem curas sem comprovação científica. Como esperado, o ozônio entra neste rol de substâncias para cura ou higienização. Aparentemente, aplicações de ozônio em pacientes infectados não ultrapassaram a fase de sugestão. Mas o uso de ozônio em câmaras em formato de túneis para higienização de humanos foi amplamente difundido e usado pelo país. O fato obrigou a ANVISA (Agencia Nacional de Vigilância Sanitária), em 7 de maio de 2020, a publicar uma nota técnica $N^{\circ} 38 / 2020$ / SEI/COSAN/GHCOS/DIRE3/ANVISA, para tratar da grande disseminação de publicidade em relação à utilização de estruturas (câmaras, cabines ou túneis) para desinfecção de pessoas, em diversas regiões do país. ${ }^{110}$ As conclusões do documento são: i) até o momento, não foram encontradas evidências científicas de que o uso dessas estruturas para desinfecção sejam eficazes no combate ao SARS-CoV-2, ii) a Anvisa somente recomenda a utilização de saneantes sobre superfícies inanimadas, de modo que a borrifação sobre seres humanos dá uso diverso àquele que foi originalmente aprovado; e iii) a borrifação de saneantes sobre seres humanos tem potencial para causar lesões dérmicas, respiratórias, oculares e alérgicas, podendo o responsável da ação responder penal, civil e administrativamente.

Mesmo contrariando os princípios da norma técnica, fabricantes com experiência na produção de câmaras juntaram-se a fornecedores de geradores de ozônio e montaram os primeiros protótipos, buscando atender possíveis demandas por soluções imediatistas. Os equipamentos produzidos, normalmente, funcionam pela aspiração de água contida em um tanque que recebeu uma carga de ozônio. A água é convertida em uma névoa no interior de uma câmara ou cabine por onde a população deve atravessar (Figura 2). As cabines apresentam laudos comprovando a eficácia do ozônio como desinfetante de vírus e bactérias, mas sem qualquer menção sobre possíveis efeitos a saúde de pessoas debilitadas. A recomendação técnica do fabricante sugere tempo de exposição máximo entre 10 e 30 segundos e a concentração, na saída do gerador, com cerca de 35 ppm de ozônio. Porém, não existem estudos que indiquem qual

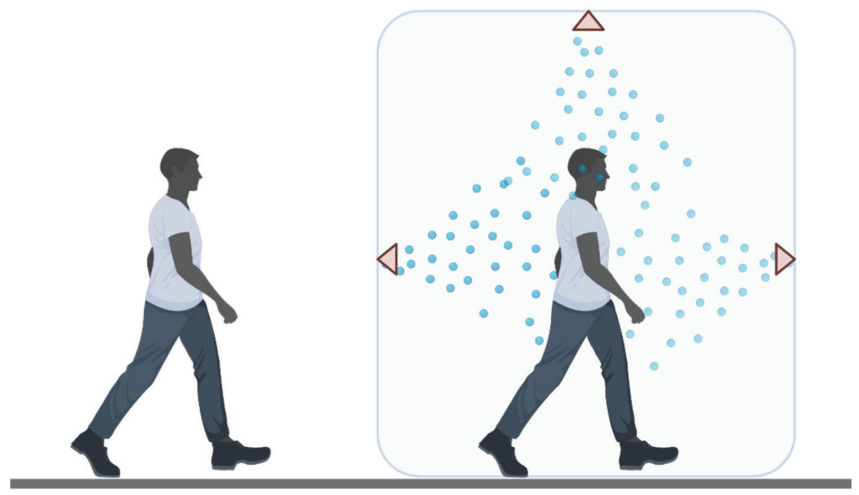

Figura 2. Representação do sistema em formato de túnel para desinfecção de humanos usando névoa contendo desinfetantes como o ozônio. (Created with BioRender.com) a concentração média do ozônio na fase gasosa no interior dessas câmaras ou qual a concentração do ozônio dissolvido nas gotículas da névoa formada.

A desinfecção de seres humanos por câmaras apresenta diversas falhas de segurança, pois não são consideradas as diferenças nas faixas etárias da população, assim como pessoas com saúde debilitada. De acordo com alguns trabalhos publicados na literatura, uma mistura de $\mathrm{O}_{3}$ e $\mathrm{O}_{2}$ apresenta potencial para ser usada para minimizar as complicações causadas pela COVID-19. ${ }^{111-114}$ Os estudos apontam uma dimuição no estresse oxidativo, que é prejudicial aos tecidos pulmonares, levando a um reestabelecimeto das atividades antioxidantes. Entretanto, cabe aletar que embora pareça promissor, mais estudos são necessários, antes da aprovação e implementação ampla de tais procedimentos. O monitoramento das espécies formadas, durante e após a exposição ao ozônio, também deverá ser realizado, assim como os efeitos, considerando curto, médio e longo prazos. Somente assim, será possível comprovar que os benefícios em utilizar o $\mathrm{O}_{3}$ são maiores que os danos que ele é capaz de ocasionar, conforme reportado na literatura.

\section{CONCLUSÕES}

O ozônio é um gás com um grande potencial de uso para melhorar a segurança biológica, porque é capaz de aniquilar um amplo espectro de patógenos que podem colocar em risco os seres humanos. Ele reage com uma variedade de compostos orgânicos naturais e pode ser um aliado do homem na destruição de compostos indesejáveis que afligem a sociedade moderna na forma de poluentes. Essas propriedades sugerem que o ozônio possui um grande potencial para aplicações diversas. Porém, também são o maior indicativo que a manipulação do ozônio requer cuidados especiais para evitar o contato do gás com seres humanos, animais e plantas. A manipulação do ozônio deve ser feita por pessoas bem treinadas e mantidas todas as condições de segurança. Urge a necessidade de uma regulamentação para o uso do ozônio, baseadas não só no objetivo do uso, mas também na segurança individual e coletiva do usuário e da população, assim como ocorreu com elementos radioativos e antibióticos, que embora sejam amplamente utilizados, seus riscos foram minimizados por regulamentações específicas.

\section{AGRADECIMENTOS}

O presente trabalho foi realizado com apoio da Coordenação de Aperfeiçoamento de Pessoal de Nível Superior - Brasil (CAPES) - Código de Financiamento 001. Os autores agradecem o apoio financeiro das agências de fomento FAPESP e CNPq.

\section{REFERÊNCIAS}

1. Seinfeld, J. H.; Contaminacion atmosferica: fundamentos físicos e químicos; Instituto de Estudos de Administracion Local: Madri, 1978.

2. Seinfeld, J. H.; Atmospheric chemistry and physics of air pollution; John Willey \& Sons: New York, 1986.

3. Ichinose, T.; Sagai, M.; Toxicology 1989, 59, 259.

4. Gelzleichter, T. R.; Witschi, H.; Last, J. A.; Toxicol. Appl. Pharmacol. 1992, 112, 73.

5. Gelzleichter, T. R.; Witschi, H.; Last, J. A.; Toxicol. Appl. Pharmacol. 1992, 116, 1.

6. Rubin, M. B.; Bull. Hist. Chem. 2001, 26, 40.

7. De Novais, V. L. D.; Ozônio: aliado e inimigo, $1^{\text {st }}$ ed., Ed. Scipione: São Paulo, 1998.

8. Kunz, A.; Freire, R. S.; Rohwedder, J. J. R.; Duran, N.; Mansilla, H.; Rodriguez, J.; Quim. Nova 1999, 22, 425. 
9. Wayne, R. P.; Chemistry of atmospheres, $3^{\text {rd }}$ ed., Oxford: New York, 2000.

10. Mudway, I. S.; Kelly, F. J.; Mol. Aspects Med. 2000, 21, 1.

11. Ruidavets, J. B.; Cournot, M.; Cassadou, S.; Giroux, M.; Meybeck, M.; Ferrières, J.; Circulation 2005, 111, 563.

12. Aulakh, G. K.; Brocos Duda, J. A.; Guerrero Soler, C. M.; Snead, E.; Singh, J.; Physiol. Rep. 2020, 8, e14463.

13. World Health Organization. Health aspects of air pollution with particulate matter, ozone and nitrogen dioxide, disponível em: http:// www.euro.who.int/document/e79097.pdf, acessada em abril 2021.

14. Liu, F.; Environ. Sci. Technol. 1998, 32, 32A.

15. Ruidavets, J.-B.; Cournot, M.; Cassadou, S.; Giroux, M.; Meybeck, M.; Ferrières, J.; Circulation 2005, 111, 563.

16. Mortimer, K. M.; Tager, I. B.; Dockery, D. W.; Neas, L. M.; Redline, S.; Am. J. Respir. Crit. Care Med. 2000, 162, 1838.

17. Bell, M. L.; Mcdermott, A.; Zeger, S. L.; Samet, J. M.; Forestry 2004, 292,2372

18. Touloumi, G.; Katsouyanni, K.; Zmirou, D.; Schwartz, J.; Spix, C.; Ponce De Leon, A.; Tobias, A.; Quennel, P.; Rabczenko, D.; Bacharova, L.; Bisanti, L.; Vonk, J. M.; Ponka, A.; Am. J. Epidemiol. 1997, 146, 177.

19. https://www.who.int/airpollution/publications/aqg2005/en/, acessada em abril 2021

20. https://www.eea.europa.eu/themes/air/air-quality-concentrations/airquality-standards, acessada em abril 2021.

21. https://www.epa.gov/criteria-air-pollutants/naaqs-table\#3, acessada em abril 2021

22. Resolução N. 491, de 19 de Novembro de 2018, http://www2.mma.gov. br/port/conama/legiabre.cfm?codlegi=740, acessada em abril 2021.

23. U.S. Food and Drug Administration, Maximum acceptable level of ozone, https://www.accessdata.fda.gov/scripts/cdrh/cfdocs/cfcfr/ CFRsearch.cfm?fr=801.415\#: :text=(1) In such a manner,C (77 deg, acessada em abril 2021.

24. Finlayson-Pitts, B. J.; Pitts, Jr, J. N.; Atmospheric chemistry: fundamentals and experimental techniques; $1^{\text {st }}$ ed.; Wiley: New York, 1986.

25. Baird, C.; Cann, M.; Química Ambiental; $4^{\text {th }}$ ed.; Bookman: Porto Alegre, 2011.

26. Moore, J. W.; Moore, E. A.; Environmental chemistry; Academic Press: New York, 1976.

27. Parrish, D.D.; Ryerson, T.B.; Holloway, J.S.; Trainer, M.; Fehsenfeld, F. C.; Atmos. Environ. 1999, 33, 5147.

28. Chan, L. Y.; Liu, H. Y.; Lam, K. S.; Wang, T.; Oltmans, S. J.; Harris, J. M.; Atmos. Environ. 1998, 32, 159.

29. Geraldino, C. G. P.; Arbilla, G.; da Silva, C. M.; Corrêa, S. M.; Martins, E. M.; Environ. Monit. Assess. 2020, 192.

30. Teixeira, E. C.; de Santana, E. R.; Wiegand, F.; Fachel, J.; Atmos. Environ. 2009, 43, 2213.

31. Arbilla, G.; Martins, E. M.; Moreira, A.; Moreira, L. F. R.; J. Braz. Chem. Soc. 2002, 13, 308

32. Wang, Y.; Wang, H.; Wang, W.; Atmosphere (Basel) 2020, 11.

33. Langford, A. O.; Brioude, J.; Cooper, O. R.; Senff, C. J.; Alvarez, R. J.; Hardesty, R. M.; Johnson, B. J.; Oltmans, S. J.; J. Geophys. Res. Atmos. 2012, 117, 1 .

34. Silva, L. M. da; Jardim, W. F.; Quim. Nova 2006, 29, 310.

35. Khadre, M. A.; Yousef, A. E.; Kim, J.-G.; J. Food Sci. 2001, 66, 1242.

36. Stern, A. C.; Air pollution: measuring, monitoring, and surveillance of air pollution, $3^{\text {rd }}$ ed., Academic Press: San Diego, 1976.

37. Sachdev, S. L.; Lodge, J. P.; West, P. W.; Anal. Chim. Acta 1972, 58, 141.

38. Bader, H.; Hoigné, J.; Water Res. 1981, 15, 449.

39. Felix, E. P.; De Souza, K. A. D.; Dias, C. M.; Cardoso, A. A.; J. AOAC Int. 2006, 89, 480 .
40. Felix, E. P.; Filho, J. P.; Garcia, G.; Cardoso, A. A.; Microchem. J. 2011, 99, 530.

41. Felix, E. P.; Cardoso, A. A.; J. Braz. Chem. Soc. 2006, 17, 296.

42. Garcia, G.; Allen, A. G.; Cardoso, A. A.; J. Environ. Monit. 2010, 12, 1325.

43. Garcia, G.; Allen, A. G.; Cardoso, A. A.; Water, Air, Soil Pollut. 2014, $225,1836$.

44. Cerrato-Alvarez, M.; Frutos-Puerto, S.; Miró-Rodríguez, C.; Pinilla-Gil, E.; Microchem. J. 2020, 154, 104535.

45. Cerrato-Alvarez, M.; Miró-Rodríguez, C.; Pinilla-Gil, E.; Sens. Actuators, B: Chem. 2018, 273, 735.

46. Komhyr, W. D.; Ann. Geophys. 1969, 25, 203.

47. Hůnová, I.; Stoklasová, P.; Schovánková, J.; Kulasová, A.; Environ. Sci. Pollut. Res. 2016, 23, 377.

48. Hagenbjörk, A.; Malmqvist, E.; Mattisson, K.; Sommar, N. J.; Modig, L.; Environ. Monit. Assess. 2017, 189, 161.

49. https://www.skcltd.com/products2/passive-samplers/ozone-test-strips. html, acessada em abril 2021

50. https://www.skcltd.com/products2/gas-detection-tubes/gastec-colourdetector-tubes/gastec-colour-detector-tubes-o.html, acessada em abril 2021.

51. Pryor, W. A.; Free Radicals Biol. Med. 1994, 17, 451.

52. Ballinger, C. A.; Cueto, R.; Squadrito, G.; Coffin, J. F.; Velsor, L. W.; Pryor, W. A.; Postlethwait, E. M.; Free Radicals Biol. Med. 2005, 38, 515.

53. Mahmoud, A.; Freire, R. S.; Quim. Nova 2007, 30, 198.

54. Kley, D.; Kleinmann, M.; Sanderman, H.; Krupa, S.; Environ. Pollut. 1999, 100, 19 .

55. Campbell, I. M.; Energy and the atmosphere: a physical-chemical approach; $2^{\text {nd }}$ ed.; John Wiley: New York, 1986.

56. Beck, J. P.; Krzyzanowski, M.; Koffi, B.; Tropospheric ozone in the European Union: the consolidated report, disponível em http://reports. eea.eu.int/TOP08-98/en/page001.html, acessada em abril 2021.

57. Peden, D. B.; Setzer, R. W.; Devlin, R. B.; Am. J. Respir. Crit. Care Med. 1995, 151, 1336.

58. Guth, D. J.; Warren, D. L.; Last, J. A.; Toxicology 1986, 40, 131

59. Broeckaert, F.; Arsalane, K.; Hermans, C.; Bergamaschi, E.; Brustolin, A.; Mutti, A.; Bernard, A.; Lancet 1999, 353, 900.

60. Valacchi, G.; Fortino, V.; Bocci, V.; Br. J. Dermatol. 2005, 153, 1096.

61. Sathishkumar, K.; Haque, M.; Perumal, T. E.; Francis, J.; Uppu, R. M.; FEBS Lett. 2005, 579, 6444.

62. Sathishkumar, K.; Gao, X.; Raghavamenon, A. C.; Parinandi, N.; Pryor, W. A.; Uppu, R. M.; Free Radicals Biol. Med. 2009, 47, 548.

63. Smith, L. L.; Lipids 1996, 31, 453.

64. Siciliano, B.; Dantas, G.; da Silva, C. M.; Arbilla, G.; J. Braz. Chem. Soc. 2020, 31, 523.

65. Boubel, R. W.; Fox, D. L.; Turner, D. B.; Stern, A. C.; Fundamentals of air pollution; $3^{\text {rd }}$ ed.; Academic Press: California, 1994.

66. Fuhrer, J.; Environ. Pollut. 2000, 109, 359.

67. Guerra, J. C.; Rodriguez, S.; Arencibia, M. T.; Garcia, M. D.; Chemosphere 2004, 56, 1157.

68. Ashmore, M.; Emberson, L.; Karlsson, P. E.; Pleijel, H.; Atmos. Environ. 2004, 38, 2213

69. Gravano, E.; Bussotti, F.; Strasser, R. J.; Schaub, M.; Novak, K.; Skelly, J.; Tani, C.; Physiol. Plant. 2004, 121, 620.

70. Grosjean, D.; Whitmore, P. M.; Cass, G. R.; Environ. Sci. Technol. 1988, $22,292$.

71. Salmon, L. G.; Cass, G. R.; Bruckman, K.; Haber, J.; Atmos. Environ. 2000, 34, 3823

72. Grontoft, T.; Henriksen, J. F.; Seip, H. M.; Atmos. Environ. 2004, 38, 59.

73. Varga, L.; Szigeti, J.; Int. J. Dairy Technol. 2016, 69, 157.

74. Kim, J.-G.; Yousef, A. E.; Khadre, M. A.; Adv. Food Nutr. Res. 2003, 45, 167. 
75. Stoker, G.; Lancet 1916, 188, 712.

76. Bocci, V.; Zanardia, I.; Valacchi, G.; Borrelli, E.; Travagli, V.; Cardiovasc. Hematol. Disord. Targets 2015, 15, 127.

77. Bocci, V.; OZONE A New Medical Drug; Springer: Amsterdam, 2005.

78. Bocci, V.; Toxicol. Appl. Pharmacol. 2006, 216, 493.

79. Bocci, V.; Borrelli, E.; Valacchi, G.; Luzzi, E.; Eur. J. Appl. Physiol. Occup. Physiol. 1999, 80, 549.

80. Ugazio, E.; Tullio, V.; Binello, A.; Tagliapietra, S.; Dosio, F.; Molecules 2020, 25,1 .

81. Wainstein, J.; Feldbrin, Z.; Boaz, M.; Harman-Boehm, I.; Diabetes Technol. Ther. 2011, 13, 1255.

82. Kushmakov, R.; Gandhi, J.; Seyam, O.; Jiang, W.; Joshi, G.; Smith, N. L.; Khan, S. A.; Med. Gas Res. 2018, 8, 111.

83. Borges, G. Á.; Elias, S. T.; da Silva, S. M. M.; Magalhães, P. O.; Macedo, S. B.; Ribeiro, A. P. D.; Guerra, E. N. S.; Journal of CranioMaxillofacial Surgery 2017, 45, 364.

84. Kim, H. S.; Noh, S. U.; Han, Y. W.; Kim, K. M.; Kang, H.; Kim, H. O.; Park, Y. M.; J. Korean Med. Sci. 2009, 24, 368.

85. Aerts, O.; Leysen, J.; Horst, N.; Lambert, J.; Goossens, A.; Contact Dermatitis 2016, 75, 123.

86. Tiwari, S.; Avinash, A.; Katiyar, S.; Aarthi Iyer, A.; Jain, S.; Saudi J. Dent. Res. 2017, 8, 105.

87. Nagayoshi, M.; Fukuizumi, T.; Kitamura, C.; Yano, J.; Terashita, M.; Nishihara, T.; Oral Microbiol. Immunol. 2004, 19, 240.

88. IARC Classifies Formaldehyde as Carcinogenic: Oncol. Times 2004, 26, 72 (DOI: 10.1097/01.cot.0000292246.11180.99).

89. Guinesi, A. S.; Andolfatto, C.; Idomeo, B. F.; Arnaldo, A. C.; Juliano, P. F.; Roberta, V. F.; Braz. Dent. J. 2011, 22, 37.

90. Tara, F.; Zand-kargar, Z.; Rajabi, O.; Berenji, F.; Akhlaghi, F.; Shakeri, M. T.; Azizi, H.; Alternative Therapies, Health and Medicine 2016, 22.

91. Di Paolo, N.; Bocci, V.; Salvo, D. P.; Palasciano, F.; Biagioli, M.; Meini, S.; Galli, F.; Ciari, I.; Maccari, F.; Cappelletti, F.; Di Paolo, M.; Gaggiotti, E.; Int. J. Artif. Organs 2005, 28, 1039.

92. Özoğul, Y. In Innovative Technologies in Seafood Processing; McClements, D. J.,; Kosker, A. R., Durmus, M., Ucar, Y., eds.; CRC Press: Boca Raton, 2019.

93. Sopher, C. D.; Battles, G. T.; Knueve, E. A.; Ozone Sci. Eng. 2007, 29, 221.

94. Crapo, C.; Himelbloom, B.; Vitt, S.; Pedersen, L.; J. Aquat. Food Prod. Technol. 2008, 8850, 125.
95. Pandiselvam, R.; Sunoj, S.; Manikantan, M. R.; Kothakota, A.; Hebbar, K. B.; Ozone Sci. Eng. 2017, 39, 115.

96. Eglezos, S.; Dykes, G. A.; J. Food Prot. 2018, 81, 795.

97. Gonçalves, A. A.; J. Aquat. Food Prod. Technol. 2016, 25, 210.

98. Violleau, F.; Pernot, A. G.; Surel, O.; J. Cereal Sci. 2012, 55, 392.

99. Chan, H. T.; Leh, C. P.; Bhat, R.; Senan, C.; Williams, P. A.; Karim, A. A.; Food Chem. 2011, 126, 1019.

100. Matheson, K. J.; Boyer, A. J.; Warren, D. H.; J. Dairy Sci. 1927, 10, 53.

101. Cotruvo, J. K. F.; WHO Guidelines for drinking-water quality 2005, 3, 13.

102. Tiwari, B. K.; Brennan, C. S.; Curran, T.; Gallagher, E.; Cullen, P. J.; O' Donnell, C. P.; J. Cereal Sci. 2010, 51, 248.

103. Kells, S. A.; Mason, L. J.; Maier, D. E.; Woloshuk, C. P.; J. Stored Prod. Res. 2001, 37, 371.

104. Diao, E.; Hou, H.; Chen, B.; Shan, C.; Dong, H.; Food Chem. Toxicol. 2013, 55, 519.

105. Mendez, F.; Maier, D. E.; Mason, L. J.; Woloshuk, C. P.; J. Stored Prod. Res. 2002, 39, 33.

106. Sandhu, H. P. S.; Manthey, F. A.; Simsek, S.; Carbohydr. Polym. 2012, $87,1261$.

107. Wang, Y.; King, J. M.; Xu, Z.; Losso, J.; Prudente, A.; J. Agric. Food Chem. 2008, 56, 7942.

108. Smith, N.; Wilson, A.; Gandhi, J.; Vatsia, S.; Khan, S.; Med. Gas Res. 2017, 7, 212.

109. Karaca, H.; Velioglu, Y. S.; Nas, S.; Toxin Rev. 2010, $29,51$.

110. ANVISA, Nota Técnica No 38/2020, https://coronavirus.rs.gov.br/ upload/arquivos/202006/12142016-nota-tecnica-28-anvisa-2020desinfeccao-de-pessoas.pdf, acessada em abril 2021.

111. Franzini, M.; Valdenassi, L.; Ricevuti, G.; Chirumbolo, S.; Depfenhart, M.; Bertossi, D.; Tirelli, U.; Int. Immunopharmacol. 2020, 88, 106879.

112. Izadi, M.; Cegolon, L.; Javanbakht, M.; Sarafzadeh, A.; Abolghasemi, H.; Alishiri, G.; Zhao, S.; Einollahi, B.; Kashaki, M.; Jonaidi-Jafari, N.; Asadi, M.; Jafari, R.; Fathi, S.; Nikoueinejad, H.; Ebrahimi, M.; Imanizadeh, S.; Ghazale, A. H.; Int. Immunopharmacol. 2021, 92.

113. Tascini, C.; Sermann, G.; Pagotto, A.; Sozio, E.; De Carlo, C.; Giacinta, A.; Sbrana, F.; Ripoli, A.; Castaldo, N.; Merelli, M.; Cadeo, B.; Macor, C.; De Monte, A.; Intern. Emerg. Med. 2020, $1,1$.

114. Wu, J.; Tan, C. S.; Yu, H.; Wang, Y.; Tian, Y.; Shao, W.; Zhang, Y.; Zhang, K.; Shao, H.; Ni, G.; Shen, J.; Galoforo, A. C.; Wu, Q.; Ming., D.; The Innovation 2020, $1,100060$. 